\title{
Gasohol enthusiasm may increase world food problem
}

A warning that growing enthusiam for the use of agricultural crops to produce automobile fuels may contribute directly to escalating food costs and shortages has come from Lester Brown, Director of the Washington-based Worldwatch Institute.

In a report financed by the United Nations Environment Programme and the Gund Foundation, published last week, Mr Brown draws attention to potential conflicts between the different users of such crops, arguing that the demand by motorists for fuel produced in this way represents a major new variable in discussions of food supply and population growth.

"The stage is set for direct competition between the affluent minority who own the world's 315 million automobiles, and the poorest segments of humanity, for whom getting enough food to stay alive is already a struggle" Mr Brown says in his report.

The rapidly rising cost of petroleum has made the use of alchohol as a fuel - either in pure form, or mixed with petrol to produce gasohol - increasingly attractive, in addition to its environmental advantages and the fact that its production can provide an important source of jobs in developing countries.

The most advanced gasohol programme is in Brazil, where according to $\mathrm{Mr}$ Brown the government has set a target of producing 10.7 billion litres of alcohol by 1985. The US also has an ambitious programme, with grants and tax credits designed to reach a domestic production level of 2 billion gallons of ethanol by the mid-80s.

Plans for developing major programmes are also under way in other food exporting countries such as Australia, New Zealand

'Food or fuel: new consumption for the world's cropland' Worldwatch Paper no 35 Worldwatch Institute, 1776 Massachusetts Avenue NW, Washington DC 20036. \$2. and South Africa. The consequence, says $\mathrm{Mr}$ Brown, is that the possibility exists for the first time of a major shift of food production capacity to non-food purposes".

Yields can be high, and could be boosted even further by a "'modest effort in plant breeding and research" he suggests. As a result, the economic conditions for the large-scale commercial production from high-yielding energy crops appears to be favourable.

But the impact on food supplies and prices could be severe, particularly at a time when increases in world food output are scarcely keeping up with population growth. In Brazil, for example which already has a net deficit of 6 million metric tons a year, meeting official targets could mean planting one fifth of the country's cropland with sugarcane, driving food prices upward and "leading to more severe malnutrition among the poor".

Similarly the US, currently the world's largest supplier of grain, would have to reduce its exportable surplus considerably to meet official production goals, as distillers take a growing share of the US grain harvest. Mr Brown estimates that an individual in the US running a car solely on alcohol would require almost ten times the cropland needed to produce food for an affluent diet. Even using only a $10 \%$ ethanol mix, the car owner's cropland requirement would double.

But the solution is not to abandon gasohol. "A carefully designed alcohol fuel programme that gave farmers a first priority in the use of ethanol for tractors, farm trucks, and irrigation pumps would be a major step toward the creation of a sustainable food production system, and of a sustainable society", Mr Brown says, followed over the longer term by a programme based on forest products and cellulosic materials of forest origin.

Sugarcane: bad-news fuel crop?

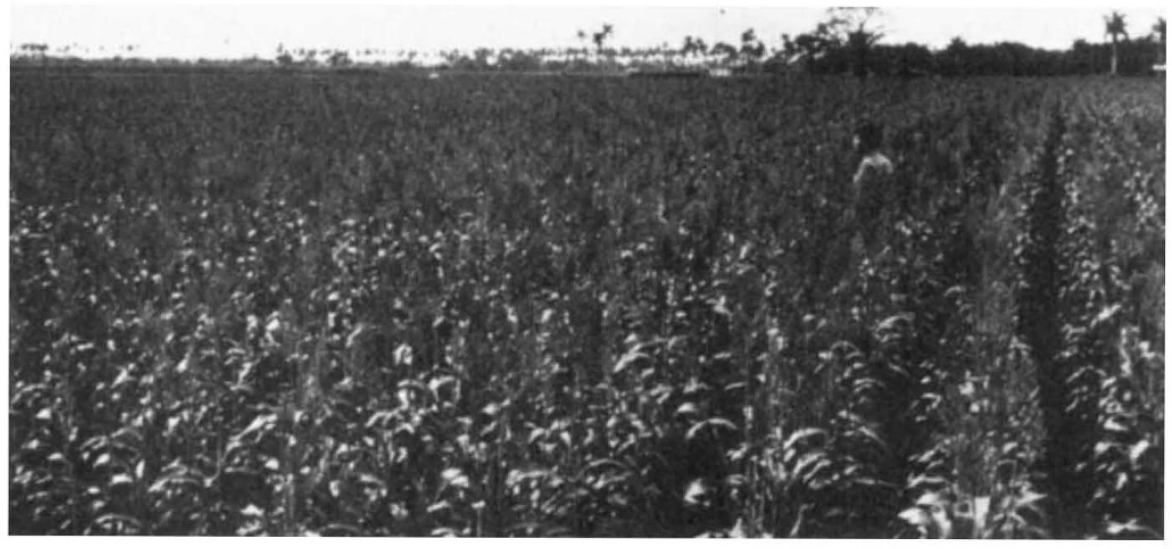

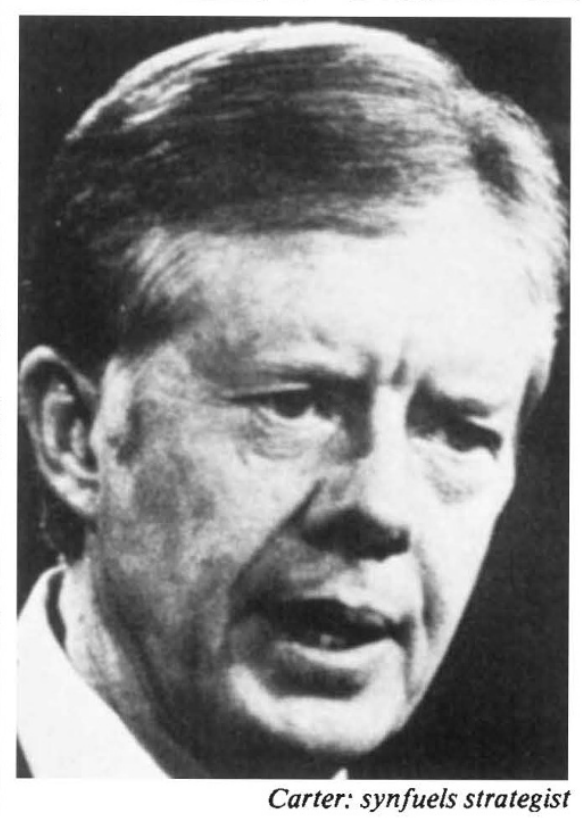

Controversy over $\$ 20$ billion synfuels programme

AFTER three months of intense negotiation, the US Congress is putting the finishing touches to legislation which will commit the government to spending $\$ 20$ billion over the next four years to stimulate the production of synthetic fuels. But the proposed legislation remains surrounded by controversy, in particular over the extent to which political interests have been allowed to override environmental and technical concerns.

The synfuels programme, a major plank in President Carter's strategy to reduce dependence on imported oil, would provide a variety of financial incentives to encourage private industry to construct plants producing synthetic oil or gas from coal, oil shale or other sources.

The proposal has been eagerly pushed by a number of constituencies, such as coal companies and engineering firms, who see it as a potential source of generous governmnent support.

But it still faces a battery of critics, from environmentalists who argue that the health and environmental implications of a crash synfuels programme are receiving inadequate attention, to some parts of the oil industry which feel that a massive federal investment, based primarily on exisiting technology, could seriously distort the future growth of the industry.

So far the environmentalists have received little comfort. They have raised numerous concerns, such as the large quantities of water needed by synfuel plants, and the potential carcinogenic 